\title{
A Dynamic and Routine-based Perspective to Analyze IT Capability
}

\author{
Bing Bai and Zhiqiong Guo*
}

Business School, Jiangsu Normal University, Xuzhou, China, 221116

\begin{abstract}
Under the tide of information economy, IT (information technology) capability greatly influences the ability of organizations to adapt to changes, and thereby to improve and preserve organizational task performance in the dynamic and complex business environment. This paper try to analyze the structure of IT capability from dynamic and routinebased perspective. According to the dynamic capability theory, IT capability can be mainly divided into two levels: IT operational capabilities and IT dynamic capabilities. The IT operational capabilities are indeed various sets of IT operating routines, while the IT dynamic capabilities are indeed IT strategic routines. We take the IT routine as a basic unit of analysis, and depict a micro-interpretation of IT capability.
\end{abstract}

Keywords: Dynamic capability, IT capability, routines.

\section{INTRODUCTION}

Currently, organizational IT systems play a significant part in this information revolution age. IT greatly influences the ability of organizations to adapt to changes, and thereby to improve and preserve organizational task performance in the dynamic and complex business environment [1]. However, IT resources alone cannot produce a sustainable competitive advantage [2]. Therefore, how to effectively use IT to gain a competitive advantage is what each business organization needs to face. Some scholars try to solve this problem from organizational capabilities perspective. In this context, the concept of "IT capability" is introduced.

IT capability is defined as "The ability to control ITrelated costs, use effectively and deploy IT-based resources in combination or co present with other re-sources and capabilities" $[3,4]$. It has become a critical resource for enterprises in the 21st century [5]. From resource-based view (RBV), IT capability is defined as the composite of underlying resources or management assets, which can offer a sustainable competitive advantage [3].

From the perspective of RBV, most scholars agree that IT capability is the ability to integrate other organizational resources through the use and disposition of one's own IT resources [4]. However, the resource-based view is still a static analysis, which cannot explain the dynamic aspect of the formation and evolution of IT capability in a complex business environment.

The emergence of dynamic capabilities theory has provided a new perspective to analyze the evolution of IT capability in more comprehensive ways. Dynamic capabilities theory regards the organizational capability as a dynamic and adaptive process, which is to integrate, reconfigure, gain and release re-sources to match rapidly changing environments
[6]. The view of dynamic capabili-ties is a kind of dynamic analysis, which can clearly explain the formation and evolution of IT capabilities in an ever-changing business environment.

\section{THEORETICAL BASIS}

\subsection{Dynamic Capability}

The dynamic capabilities theory has gained increasing attention in the past few years, not only in strategic management but also in many other aspects within the area of organization theory. The concept of dynamic capability is proposed by Teece [6], which is defined as "the ability to integrate, build, and reconfigure internal and external competences to address rapidly changing environments". Afterward, many scholars further studied the concept of dynamic capabilities. Eisenhardt [7] describes the dynamic capability as "The firm's processes that use resources - specifically, the processes to integrate, reconfigure, gain and release resources to match and even create market change. Dynamic capabilities thus are the organizational and strategic routines by which firms achieve new resource configuration as markets emerge, collide, split, evolve, and die". Zollo and Winter [8] argue that "A dynamic capability is a learned and stable pattern of collective activities through which the organization systematically generates and modifies its operating routines in pursuit of improved effectiveness". Zahra regards the dynamic capabilities as "the abilities to reconfigure a firm's resources and routines in the manner envisioned and deemed appropriately by its principal decision maker(s)" [9]. In the light of these statements, we can see that the concept "routines" is very important to explain dynamic capabilities. From a routines-based view, dynamic capabilities have been defined as abilities (or capacities) but also as processes or routines [10]. Therefore, we can analyze dynamic capabilities from the routines-based perspective.

\subsection{Organizational Evolutionary Theory}

According to evolutionary perspectives on organizational theory, organizations are only carriers of competencies that 
are embedded in specific routines [11]. Routines are essentially a set of organizational capabilities, which is a body of knowledge about the methods and functions of an organization and are seen as the "Building blocks of organizational capabilities"' [12].

Some literature defines capabilities as bundles of interrelated yet distinct routines [13-15]. Routines are considered as the appropriate units of selection for capability evolution $[16,17]$. Therefore, our study takes routines as the basic analysis unit of capabilities, analyzing the formation and evolution of IT capabilities.

\section{A ROUTINES-BASED APPROACH TO STUDY IT CAPABILITIES}

\subsection{Organizational Routines}

Routines have been defined by many prior studies. Nelson and Winter [18] defined organizational routines from the evolutionary perspective as "the ways of doing things". Teece described routines as "the way things are done or patterns of activities" [6]. Routines are the basic components of organizational behavior, and the repository of organizational capabilities [16-18]. Referring to the prior studies of routines, we represent routines as the vector of organizational capabilities. The organizational routines are the bridge that connects organizational resources and capabilities. From a routines-based view, the organizational capabilities can be mainly divided into two levels: the "first-order" capabilities and the "high-order" capabilities [20]. Dynamic capabilities can be regarded as the high-order organizational capabilities, and the first-order organizational capabilities are called operational capabilities [8]. Here, the operational capabilities are indeed some various sets of operating routines. While they are built, integrated and reconfigured, these operational routines will become dynamic capabilities [6]. In other words, dynamic capabilities are indeed the organizational strategic "routines" by which the organization generates and modifies its operating routines and achieve some "new source configurations as markets emerge, collide, spit, evolve, and die" [7, 12].

This routines-based approach to capabilities allows the disentanglement of those into specific and identifiable routines, thereby outlining possible pathways to capability building and evolution.

In the light of this study, we take the routine as a basic analysis unit of capabilities, and depict a micro-interpretation of capabilities.

\subsection{Operating Routines and Strategic Routines}

According to the former analysis, the organizational capabilities can be mainly divided into two levels, the "firstorder" capabilities and the "high-order", whereas Winter (2003) called them operational capabilities and dynamic capabilities separately. The former are indeed some various sets of operating routines. With the organizational managers' decision choices, they transform inputs (resources) into special types of outputs $[8,12,18]$. While the later are the abilities to build, integrate and reconfigure these operational capabilities (operating routines) [6]. They can be seen here as some rules of modification of operating routines that enable high-adaptive behavior [7]. That is, dynamic capabilities are indeed the organizational and "strategic routines" by which the firm generates and modifies its operating routines and achieve some "new source configurations as markets emerge, collide, spit, evolve, and die" [7, 8, 18]. They govern the rate of changes of the operating routines [19], and influence the firm's outputs indirectly via the operational capabilities $[8,12,18,20]$.

\subsection{Towards a Dynamic View on IT Capability}

The information technology (IT) capability of an enterprise is very important to improve organizational performance and capabilities in the IT environment [21]. Different researchers have conceptualized IT capability from different perspectives. From a resource-based perspective, IT capability is defined as "The ability to control IT-related costs, use effectively and deploy IT-based resources in combination or co present with other re-sources and capabilities" $[3,4]$. But the RBV is still a sort of static analysis, and it is difficult to explain the formation and evolutionary process of IT capabilities in a dynamic and complex business environment. Consequently, some scholars study IT capability from the dynamic perspective. Sambamurthy and Zmud (2000) hold that "IT capabilities are combinations of IT based assets and routines that support business conduct in value added ways" [22]. They further pointed out that "IT capabilities apply skills and routines that evolve very rapidly and are typically acquired and retired in a discontinuous fashion". These various notions of IT capabilities are part of the pioneering efforts to offer a richer understanding of IT capability.

According to the former analysis of organizational capabilities, the IT capability, which is also one of the organizational capabilities, can be mainly divided into two levels: IT operational capabilities and IT dynamic capabilities. The IT operational capabilities are indeed various sets of IT operating routines, which transform IT resources into special types of outputs $[12,18]$, while the IT dynamic capabilities are the abilities that build, integrate and reconfigure these IT operational capabilities (operating routines) [6]. Here, IT dynamic capabilities are described as high-level routines or bundles of routines $[12,18,19]$.

\subsection{The Structure of the IT Routine}

The structure of a routine can be divided into three aspects: ostensive aspect, performative aspect, and artifacts [23]. Here, the ostensive aspect is abstract patterns that participants use to guide, account for and refer to specific performances of a routine. The performative aspect refers to actual performances by specific people, at specific times, in specific places of a routine. Artifacts are physical manifestations of the organizational routine.

Similarly, IT routines also can be expressed from these three aspects. The ostensive aspect of IT routines refers to IT enabled intangible capabilities (or routines) [24], which are the "high-order" IT capabilities; the performative aspect of IT routines can be the IT human resources capability, and the artifact is the IT infrastructure capability (Fig. 1). 


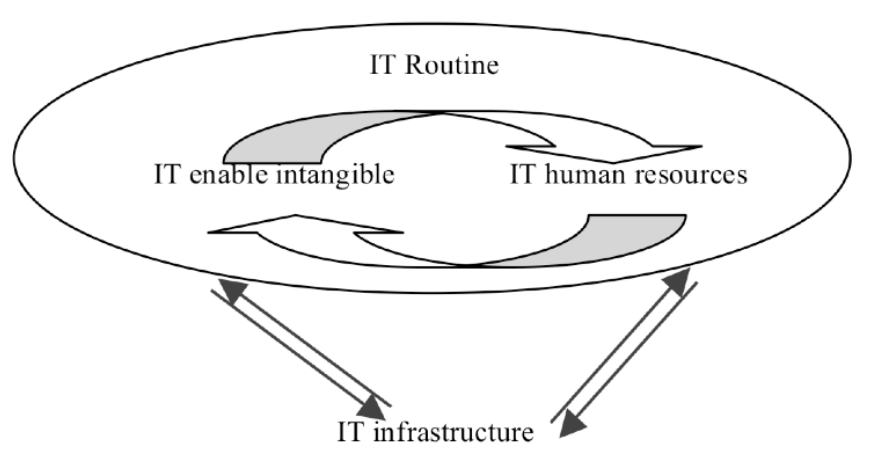

Fig. (1). The structure of IT routine.

\section{SIMULATE THE PROCESS BY SWARM}

\subsection{From Five Dimensions to Measure IT Capability}

According to the existing literature, many scholars use Value, Scarcity, Imitation, Replacement, and Extensity to measure organizational capability. IT capability, as a kind of organizational capability, can also be measured by the five dimensions. We define the capability as followed:

$$
C=\left\{C_{V}, C_{S}, C_{I}, C_{R}, C_{E}\right\}
$$

\subsection{Construction of the Simulation Model}

We design the agent in term of the former analysis. The agents include Market space, enterprise, IT routines, IT capability and so on. In the same time, we also define the agents' attributes and the ruler of agents' interaction. Finally, we use agent-based simulation platform-Swarm to realize the simulation model.

\subsection{Analysis of the Simulation Result}

In order to perform this model, we run several simulation tests to analyze the sensitivity of the parameters, and get the final parameters. From simulation schedule 1 to 600 , we select 10 enterprises randomly to analyze the change of its IT capabilities and it effect for the organizational performance. The simulation result is following (Fig. 2).

As we can see from the graph, the 10 enterprises' IT capability change steadily with the simulation experiment running. According to the former analysis, the IT capability, as one of the organizational capabilities, can promote the enterprise performance. So, in most instances, the changes between IT capability and enterprise profits change is consistent. Take enterprise 10 (deep green curve) as an example, the IT capability of enterprise 10 shows a rise tendency as a whole, despite there are some fluctuations. Meanwhile, the profits of enterprise 10 presents similar changes. The similar changes are also with enterprise 1(blue curve), enterprise 2(orange curve), enterprise 5(red curve) and so on. These indicate that IT greatly influences the ability of organizations to adapt to changes, and thereby to improve and pre-serve organizational task performance in the dynamic and complex business environment [1]. However, there are also exceptions in some cases. The enterprise 4 (pale green curve) and enterprise 3 (yellow curve) show the opposite changes. These mean IT capability alone cannot always bring better
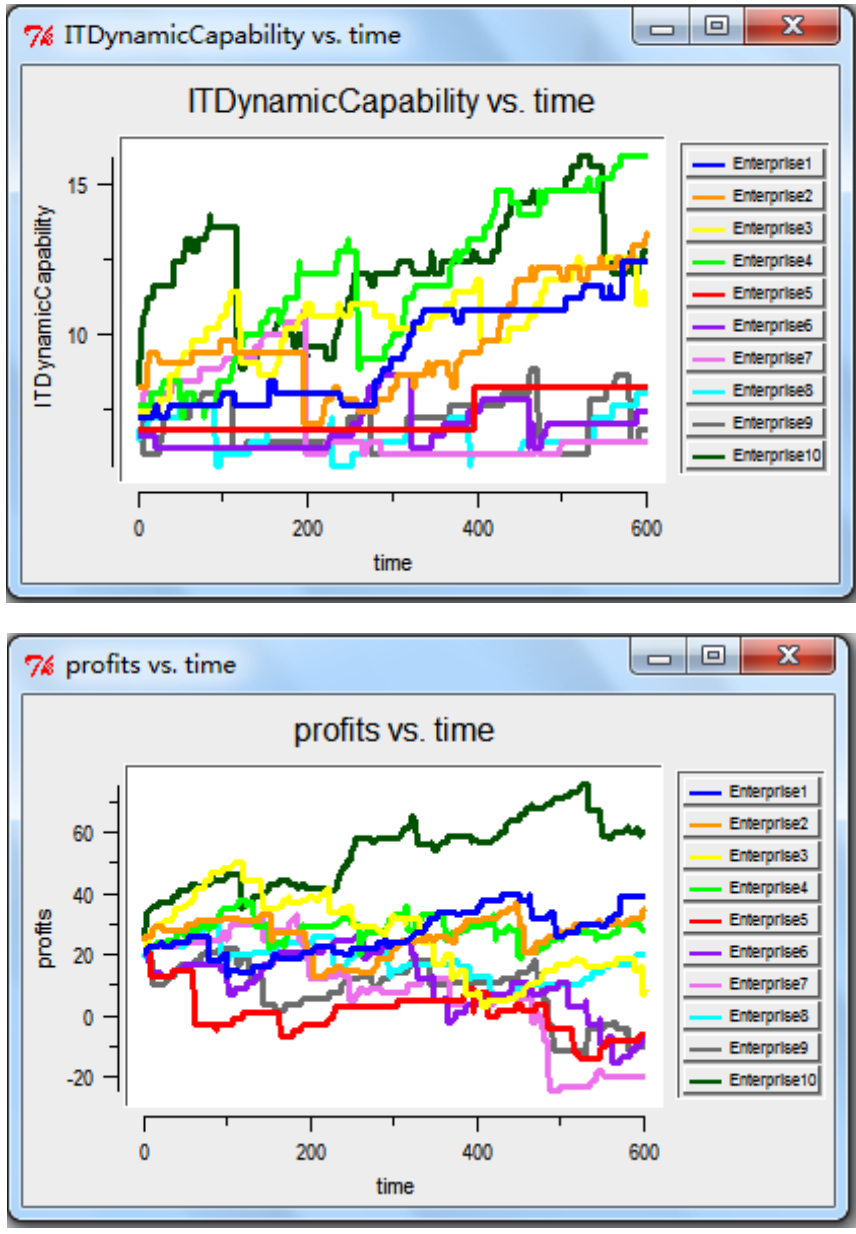

Fig. (2). The simulation output results.

performance. IT capability need to combine or co present with other resources and capabilities.

\section{CONCLUSION}

This paper, from the routine-based and dynamic capability perspective, analyzed enterprise IT capability. We take the IT routine as a basic unit of analysis, and depict a microinterpretation of IT dynamic capabilities. Through modeling the simulation model, using the Swarm simulation platform, we analyzed the relationship between IT capability and organization performance, and drew the following conclusions:

1) From the dynamic capability perspective, IT capability can be mainly divided into two levels: IT operational capabilities and IT dynamic capabilities. The IT operational capabilities are indeed various sets of IT operating routines, while the IT dynamic capabilities are indeed IT strategic routines.

2) From the routine-base view, the IT capability is composed of a series of IT routines. According to Pentlan's definition, the structure of IT routine can be divided into three aspect: IT infrastructure routine, IT human resource routine, and IT enabled in-tangible routine.

3) The simulation results show that the relation-ship between IT capability and organization performance is very complicated. On the on hand, in most cases, the promotion 
of IT capability can enhance the enterprise performance. On the other hand, IT capability alone cannot always bring better performance. IT capability need to combine or co present with other resources and capabilities.

However, from dynamic and routine-based perspective to study IT capability are an exploratory research, especially using agent-based simulation methodology. This simulation model of this paper is still relative simple. There are many factors need to be considered. All these are the work to be further studied.

\section{CONFLICT OF INTEREST}

The authors confirm that this article content has no conflict of interest.

\section{ACKNOWLEDGEMENTS}

The paper has been sponsored by the National Natural Science Foundation of China (No. 71302188), Philosophy and Social Science Fund of Colleges and Universities in Jiangsu Province (No. 2013SJB6300032) and Qing Lan Project.

\section{REFERENCES}

[1] C. S. Leem, S. Kim, "Introduction to an integrated methodology for development and implementation of enterprise information systems", J. Syst. Softw., vol. 60, no. 3, pp. 249-261, 2002.

[2] T. C. Powell, A. Dent-Micallef, "Information tech-nology as competitive advantage: the role of human, business, and technology resources”, Strategy Manag. J., vol. 18, no. 5, pp. 375-405, 1997.

[3] J. W. Ross, C. M. Beath, D. L. Goodhue. "Develop long-term competitiveness through IT assets", Sloan Manag. Rev., vol. 38, no. 1, pp. 31-33, 1996.

[4] A. S. Bharadwaj, "A resource-based perspec-tive on information technology capability and firm performance: an empirical investigation", MIS Quarterly, vol. 24, no. 1, pp. 169-196, 2000.

[5] A. S. Bharadwaj, S. G. Bharadwaj, B. R. Konsynski, "Information technology effects on firm performance as measured by Tobin's q", Manag. Sci., vol. 45, no. 7, pp. 1008-1024, 1999.

[6] D. Teece, G. Pisano, A. Shuen, "Dynamic capabili-ties and strategic management”, Strategic Manag. J., vol. 18, no. 5, pp. 09-33, 1997.
[7] K. M. Eisenhardt, J. A. Martin,"Dynamic capabilities: what are they? Strategic Manag. J., vol. 21, no. 1, pp.1105-1121, 2000.

[8] M. Zollo, S. G. Winter, "Deliberate learning and the evolution of dynamic capabilities", Organ. Sci., vol. 13, no. 3, pp. 339-351, 2002.

[9] S. A. Zahra, H. J. Sapienza, P. Davidsson, "Entrepreneurship and dynamic capabilities: A review, model and research agenda", $J$. Manag. Stud., vol. 43, pp. 917-955, 2006.

[10] I. Barreto, "Dynamic capabilities: A review of past research and an agenda for the future", J. Manag., vol. 36, no. 1, pp. 256-280, 2010.

[11] H. Aldrich, "Organizations evolving, Sage Publica-tions", Thousand Oaks, CA, 1999.

[12] Winter. Four Rs of profitability: rents, resources, routines and replication. in: C.A. Montgomery(Ed.), Resource-based and evolutionary theories of the firm, Kluwer, Boston, MA, 1995.

[13] R. Amit, P. J. Schoemaker, "Strategic assets and organizational rent”, Strategic Manag. J., vol. 14, no. 1, pp. 33-46, 1993.

[14] R. Henderson, I. Cockburn, "Measuring competence? Exploring firm effects in pharmaceutical research", Strategic Manag. J., vol. 15 , pp. 63-84, 1994.

[15] T. Hult, D. J. Ketchen Jr., E. L. Nichols Jr., "Organizational learning as a strategic resource in supply management", J. Oper. Manag., vol. 21, no. 5, pp. 541-556, 2003.

[16] J. G. March, M. Schultz, X. Zhou, "The dynamics of rules: change in written organizational codes", Stanford University Press, Stanford, CA, 2000.

[17] J. G. March, "Exploration and exploitation in organizational learning”, Organ. Sci., no. 2, pp. 71-87, 1991.

[18] R. Nelson and S. G. Winter, "An Evolutionary Theory of Economic Change", Harvard University Press: Cambridge, MA, 1982.

[19] D. J. Collis, "Research note: how valuable are organizational capabilities", Strategic Manag. J., vol. 18, pp.143-152, 1994

[20] P. Abella, T. Felin, N. Foss, "Building micro-foundations for routines, capabilities, and performance links", Manag. Dec. Eco., vol. 29, pp. 489-502, 2008.

[21] C. Y. Yoon, "Measuring enterprise IT capability: A total IT capability perspective", Knowledge-Based Syst., vol. 24, no. 1, pp. 113$118,2011$.

[22] V. Sambamurthy, R. W. Zmud, "Managing IT for success: The Empowering Business Partnership", Morristown, NJ: Financial Executives Research Foun-dation, 1992.

[23] B. T. Pentland, M. S. Feldman, "Organizational routines as a unit of analysis", Industr. Corporate Change, vol. 14, no. 5, pp.793-815, 2005 .

[24] Z. Qingfeng, Z. Daqing, "The Impact of IT Capability on Enterprise Performance: An Empirical Study in China. in: WiCOM, pp. 1-6, 2008.

\footnotetext{
Received: September 22, 2014

Revised: November 30, 2014

Accepted: December 02, 2014

(C) Bai and Guo.; Licensee Bentham Open.
}

This is an open access article licensed under the terms of the Creative Commons Attribution Non-Commercial License (http://creativecommons.org/licenses/by-nc/3.0/) which permits unrestricted, non-commercial use, distribution and reproduction in any medium, provided the work is properly cited. 